\title{
Sound Radiation from a Supersonic Jet Passing Through a Partially Open Exhaust Duct
}

\author{
M. Kandula \\ ASRC Aerospace \\ NASA Kennedy Space Center, Florida 32899, USA \\ e-mail: max.kandula-1@nasa.gov
}

The radiation of sound from a perfectly expanded Mach 2.5 cold supersonic jet of $25.4 \mathrm{~mm}$ exit diameter flowing through a partially open rigid-walled duct with an upstream J-deflector has been studied experimentally. In the experiments, the nozzle is mounted vertically, with the nozzle exit plane at a height of 73 jet diameters above ground level. Relative to the nozzle exit plane (NEP), the location of the duct inlet is varied at 10, 5, and -1 jet diameters. Far-field sound pressure levels were obtained at 54 jet diameters above ground with the aid of acoustic sensors equally spaced around a circular arc of radius equal to 80 jet diameters from the jet axis. Data on the jet acoustic field for the partially open duct were obtained and compared with those with a free jet and with a closed duct. The results suggest that for the partially open duct the overall sound pressure level (OASPL) decreases as the distance between the NEP and the duct inlet plane decreases, while the opposite trend is observed for the closed duct. It is also concluded that the observed peak frequency in the partially open dict increases above the free jet value as the angle from the duct axis is increased, and as the duct inlet plane becomes closer to the NEP.

\section{Introduction}

The acoustic loads in a launch vehicle environment arising from supersonic turbulent exhaust jets of rocket engines induce severe random structural vibrations of vehicle components, encapsulated payloads, and ground support equipment in the immediate vicinity of the launch pad $[1,2]$. In recent years there has been considerable interest in the design of exhaust duct systems devoid of water injection for launch vehicles for jet noise mitigation purposes. Clean (dry) launch pads with ducted exhausts are preferable to those traditionally fitted with water 
injection systems for sound suppression with regard to operational costs and the frequency of launches. Thus the overall process of sound emission from ducted rocket exhausts is of great practical interest in the understanding, design and optimization of sound suppression systems for launch vehicles.

While experimental and theoretical studies on sound suppression with water injection for jet and rocket engine exhausts are rather extensive [3-8], experimental investigations on sound reduction with ducted (confined) turbulent supersonic exhausts are relatively few, although a number of studies were reported on enclosed subsonic flows typical of turbofan engine inlet/exhaust ducts (for example, Eversman \& Roy [9]; Ozyoruk and Long [10]). The totality of the far-field sound from ducted supersonic exhausts is composed of the transmission of sound from the free supersonic jet (upstream of the duct inlet) to the far-field, transmission of sound within the duct, and radiation of sound from the duct exit and the subsonic jet (exiting the duct) to the far-field. Recent experiments on enclosed duct (closed and partially open) by the author [11,12] with a supersonic jet passing through a rigid-walled duct with an upstream $\mathrm{J}$-deflector have indicated that the jet confinement has a significant effect on sound emission and directivity, suggesting that the duct is modifying the sound generation and propagation. An experimental and numerical study of sound propagation from a supersonic jet passing through a closed duct was recently presented by the author [13].

The present study derived primarily from [11] is concerned with experimental simulation of the effect of a partially enclosed duct on the mitigation of radiated noise from supersonic jet.

\section{Description of the Experimental Setup}

A detailed description of the experimental facility for the ducted jet configuration is presented in [11], and the test facility is only briefly described here.

\subsection{Duct and Nozzle Configuration}

Figure la shows the geometry of the jet-duct configuration considered in the experimental data [11]. A photographic view of the nozzle and the duct setup is sketched in Fig. 1b, showing the structure support of the duct and the nozzle. A scaled aluminum exhaust duct with an upstream J-deflector (30-degree inclination to the vertical) was fabricated and installed under the nozzle. The exit cross section of the duct is $152 \mathrm{~mm} \mathrm{x} 305 \mathrm{~mm}$. The duct wall thickness is $6.35 \mathrm{~mm}$. The exhaust duct can be positioned at desired levels relative to the nozzle exit plane (NEP). The origin of the coordinate system lies in the ground plane, with the $y$-axis coinciding with the jet axis. In 
the case of partially open exhaust duct, the top side of the duct remains open, whereas the closed duct corresponds to the situation where all the four sides of the duct are closed. The nitrogen jet impinges vertically on an upstream Jdeflector ( $30 \mathrm{deg}$. to the vertical) of the duct before exiting horizontally through the duct. The nozzle exit is held fixed at 73 jet diameters $(1.85 \mathrm{~m})$ above the ground level. Relative to the nozzle exit plane, the duct inlet is varied at 10,5 and -1 jet diameters, the last position referring to the condition where the NEP is below the duct inlet.

Typical chamber and nozzle conditions for the scale-model test series considered here are displayed in Table 1. The Mach number of the exhaust jet $M_{j}$ is 2.5 , and the jet Reynolds number $\operatorname{Re}_{j}$ is $2.3 \times 10^{6}$. The jet is perfectly expanded (nozzle exit pressure $p_{j}$ equals the ambient pressure $p_{\infty}$ of $1.01 \times 10^{5} \mathrm{~N} / \mathrm{m}^{2}$ ). The ambient temperature $T_{\infty}$ is $294 \mathrm{~K}$. The exit static temperature of the jet $T_{j}$ is $123 \mathrm{~K}$, indicating that it is a cold jet, as the nozzle exit temperature is colder than the ambient temperature. The Mach 2.5 convergent-divergent nozzle was designed on the basis of characteristic method and is made of stainless steel. The nozzle has an exit diameter of $25.4 \mathrm{~mm}$, which compares with about $1 \mathrm{~m}$ exit diameter typical of large rocket engines.

No foam or wedge is installed on the ground wall to minimize any sound reflection. There is also no obstruction between the microphones and the ground. The plenum upstream of the nozzle has a diameter of $101.6 \mathrm{~mm}$ (4 nozzle diameters), and it is believed that the rig noise from the jet upstream is not appreciable.

\subsection{Flow and Acoustic Measurements}

The chamber conditions (pressure and temperature) are measured by a pressure gauge and thermocouple mounted on the chamber wall. From the measurement of the total pressure and the static pressure at the NEP, the exit Mach number is computed with the aid of pitot tube formula [14] due to Lord Rayleigh. Bruel \& Kjaer Model 4189 microphones of $12.7 \mathrm{~mm}$ diameter were used for recording the sound pressure. The sensors have a frequency range of $6.3 \mathrm{~Hz}$ to $20 \mathrm{kHz}$, and a dynamic range of 14.6 to $146 \mathrm{~dB}$. There is no built-in low-pass filter for the microphone. Also no filter setting (band-pass, low pass or high pass) is incorporated in the data acquisition system.

The acoustic field surrounding the nozzle/duct configuration was measured by an array of acoustic transducers (microphones 1 through 9) placed azimuthally at 22.5-degree increments (Fig. Ic). It should be pointed out that microphone 5 (at $0 \mathrm{deg}$ ) is active only for the free jet, and not active for the ducted jet case. The sensors were placed azimuthally at 80 nozzle exit diameters from the jet axis (thus representative of far-field condition), and at a height of 54 jet diameters above ground. The vertical position of the microphones relative to the NEP and the J-deflector 
duct are indicated in Figs. Id, le, and If for the case of $h / d_{j}=10,5$ and -1 respectively. In particular, the microphones are respectively about $4 d_{j}$ above the top wall of the horizontal portion of the duct exit plane, $1 d_{j}$ below the top wall of the horizontal potion of the duct exit plane, and $1 d_{j}$ below the bottom wall of the duct exit plane. This physical consequence leads to the noise shielding from the duct to the microphones.

The azimuthal array is in a plane parallel to the ground and centered on the jet axis. Also, the array is at a polar angle of 76.6 deg relative to the downstream axis at the nozzle exit. This polar angle is chosen here considering that the microphones are located downstream of the duct exit plane at 80 nozzle diameters away from the jet axis (farfield condition) and at a height corresponding to the duct exit plane region when the duct inlet plane is 5 nozzle diameters relative to the NEP (representing the average relative position in the experiment). The polar angle chosen here is not in the peak noise radiation direction which is about $50 \mathrm{deg}$ for free supersonic jets typical of standard chemical rockets [15]. The peak angle for the free jet is modified in the presence of the duct especially as the NEP becomes closer to the duct inlet.

Time history measurements are made of chamber pressure, chamber temperature, and pitot and static pressures at the NEP. These measurements serve to indicate the time at which steady-state conditions are achieved. Generally, it takes about $60 \mathrm{~s}$ for steady flow conditions to prevail. As soon as the flow becomes steady, recording of acoustic data begins. Pressure-time data from the microphones are processed by the data acquisition system. The data are sampled at a rate of 125,000 samples/s so that sound frequencies up to $60 \mathrm{kHz}$ can be recorded. With the aid of LabVIEW software, the time domain data are processed in the form of narrowband spectra, octave-band sound pressure levels (SPL) and overall sound pressure levels (OASPL) at each location. The data are not scaled to any other distance but as measured.

Only steady state flow data are acquired, and transient flow data are not considered in this investigation. Launch (lift-off) acoustics is composed of ignition overpressure (waves representing predominantly transient flow effects) followed by a more intense jet noise (representing predominantly quasi-steady flow conditions). The study of transient flow effects on acoustics is outside the scope of the present investigation.

\section{Physical Considerations}




\subsection{Phenomena of Sound Radiation in the Open-Duct Configuration}

The phenomenon of sound radiation from a supersonic jet passing through a partially open exhaust duct is exceedingly complex. The overall process can be roughly broken into three constituent portions: Mach wave radiation from a free supersonic jet, jet impingement on the duct wall, and scrubbing noise. Initially the free supersonic jet is subject to partial noise shielding of Mach wave radiation by the duct upon entering the duct and during its travel through the vertical portion of the duct prior to impingement on the duct. Measurements on supersonic jets [15-17] have shown that noise sources are distributed over a region extending to about 15 jet diameters from the nozzle exit, with the peak noise source located roughly near the end of the potential core (8-10 jet diameters downstream of the nozzle exit). Entrainment of surrounding air is also occasioned as the jet mixing layer thickens.

Once the jet impinges on the duct, the physical process is similar to the jet impinging on a normal or an inclined plate. In practice, it is similar to the jet impinging on the ground (JSF vertical landing and take-off) or impinging on the jet blast deflector of flying deck of the aircraft carrier. Shock waves form upstream of the impinging jet wall, considering that in the present experiment the jet is possibly supersonic while the jet impinges on the duct. Experimental studies by Krothapalli et al. [18] suggest that a 1.5 Mach perfectly expanded jet when impinging on a flat surface about 3 to 5 jet diameters from NEP produces an amplification of as much as $8 \mathrm{~dB}$ in the near-field. Increases in surface pressure were noted in the measurements of Lamont et al. [19] with underexpanded air jets impinging on normal and inclined plates.

Following the jet impingement on the duct wall, the jet changes direction, and proceeds downstream in the horizontal portion of the duct. For a jet passing through a partially open duct, the physical phenomenon is similar to the jet passing through a solid plate (bottom surface of airfoil or flying deck of carrier), which brings about scrubbing noise $[20,21]$. As the jet spreads downstream, the scrubbing noise appears while the jet plume interacts with the duct (plate, ground, etc.) resulting in substantial noise amplification. With regard to the present experimental condition, the scrubbing noise possibly presents as a dominant noise source. In this connection fluidstructure interaction and flow-induced vibration likely manifest themselves.

\subsection{Relevance to Full Scale (Scaling Considerations)}


The testing jet plume contain nitrogen gas only. Actual rocket exhausts have different composition: for example, a liquid rocket engine (Shuttle SSME using $\mathrm{LH}_{2} / \mathrm{LO}_{2}$ ) has typical nozzle exit plane composition of primarily $\mathrm{H}_{2} \mathrm{O}$ and $\mathrm{H}_{2}$ with mole fractions of 0.73 and 0.26 respectively. The nozzle exit temperature is about $725 \mathrm{~K}$ (hot jet), the exit Mach number is about 4, and the exit jet Reynolds number is about $3 \times 10^{6}$. The isentropic exponent is about 1.2 (displaying real-gas behavior) at the nozzle exit. On the other hand full scale nozzle exit Mach number for a typical solid rocket nozzle is about 3.

Experimental data show that in turbulent jets the jet Reynolds number is known to influence the mixing process and entrainment only weakly. The compressibility effects influence the jet spread, suggesting that the shear layer growth rate relative to the incompressible flow decreases with an increase in convective Mach number of the jet (which is roughly proportional to the jet exit Mach number), see $[22,23]$. The shear layer growth rate depends also on the velocity ratio (jet centerline to freestream) and relatively weakly with the density ratio (jet to freestream). As the dominant variable for jet spread is the jet exit Mach number, the current condition of Mach 2.5 for the exit Mach number is considered representative of practical circumstances.

In full scale the typical duct dimensions are of the order of $10 \mathrm{~m} \times 20 \mathrm{~m}$, and the duct wall thickness is of the order of $0.25 \mathrm{~m}$. The duct wall material is made of A36 structural steel. In the actual launch pad, the bottom of the duct is attached to the ground. In the present scale model, the duct wall is sufficiently thick that no appreciable flowinduced vibration and noise is expected. No appreciable vibration from the duct support is observed in the actual experiment with flow.

\section{Results and Discussion}

\subsection{Overall Sound Pressure Level (OASPL)}

Figure 2a shows a comparison of the OASPL for free jet with those of a jet passing through a partially open duct, with the NEP located at different heights $h$ relative to the duct inlet. It represents the sound directivity in the ducted jet system, with data taken along a $2.03 \mathrm{~m}$ arc radius about the jet axis, and in a horizontal plane $1.37 \mathrm{~m}$ above the ground level [11]. While there is axial symmetry of the OASPL for the free jet, there is considerable directivity of the OASPL in the presence of exhaust duct, as is to be expected. The OASPL increases as the distance between the NEP and the duct inlet plane increases. This trend is believed to be due to increased Mach wave radiation from the free jet and also due to a decrease in the jet impingement noise as the distance between the NEP 
and the duct inlet is increased. In general, the OAPSL near the duct axis for partially open ducts are considerably higher than that for the free jet case. It appears that only for the range of angles $70-90$ deg to the jet axis, reduction in OASPL are achieved with the partially open duct, while for the remaining region the OASPL actually increases. The noise reduction (relative to the free jet) appearing in the range of 70 to 90 deg to the duct axis is perhaps contributed by the noise shielding from the side wall of the duct. The increase of OASPL for the remaining region (compared to the free jet case) may be due to the flow deflection.

Referring to the closed duct case (Fig. 2b) for purposes of comparison, reductions in OASPL are achieved for the region with the range of angles from 45 to $90 \mathrm{deg}$, with reductions of as much as $3 \mathrm{~dB}$. However for the case of $h / d_{j}=-1$ at an azimuthal angle of $90 \mathrm{deg}$, the OAPSL for the closed duct exceeds that for the open duct. The foregoing results thus suggest that closed ducts are generally preferable to partially open ducts as far as sound mitigation is concerned. From a safety point of view, open ducts are preferable to closed ducts if any unburned hydrogen enters the duct.

For the open duct case, the OASPL is the smallest for $h / d_{j}=-1$ (NEP below the duct inlet plane), whereas in the case of closed duct, the OASPL is the smallest for $h / d_{j}=10$ (NEP above the duct inlet plane). It is evident from Figs. $2 \mathrm{a}$ and $2 \mathrm{~b}$ that the trends for the partially open duct are contrary to those of the closed duct with regard to the OASPL variation as a function of the distance between the NEP and the duct inlet. In general, the OASPL comparisons for the partially open duct and the closed duct reveal that there is likely an optimum distance between the NEP and the duct inlet for minimizing the sound power.

\subsection{Spectral Sound Pressure Level}

Figure 3 presents the comparisons of spectral distribution of sound power level for the free jet and the partially open duct configuration. Figs. 3a displays the SPL distribution for the free jet. Figs. 3b-3d presents the spectral distribution of sound power level with the duct inlet respectively at $0.254 \mathrm{~m}$ below the NEP, $0.127 \mathrm{~m}$ below the $\mathrm{NEP}$, and $0.0254 \mathrm{~m}$ above the NEP $(10,5$ and -1 jet diameters relative to the NEP).

For the free jet case (Fig. 3a) the spectral distribution of SPL is symmetric, independent of the azimuthal position of the microphone. A peak frequency of about $4 \mathrm{kHz}$ is noticed, and agrees with the estimated value based

on a Strouhal number $S t\left(=f d_{j} / u_{j}\right)$ of 0.2 , typical of jet exhausts [13]. Here the quantity $f$ denotes the frequency. The free jet shows some asymmetry in the spectra (2 to $5 \mathrm{~dB})$ in the high frequency range of 4-8 $\mathrm{kHz}$, which is 
perhaps due to the non-anechoic character of the experimental facility and to the presence of the neighboring structures (see Fig. 1b).

In the open duct case (Fig. 3b) with duct inlet $0.254 \mathrm{~m}$ below the NEP, the peak frequency near $\theta=0 \mathrm{deg}$. (corresponding to the duct axis) is about $4 \mathrm{kHz}$, which is close to the free jet value. However, the peak frequency increases as the angle from the duct axis is increased. The results also suggest that as the height of the duct inlet plane above the ground increases (with the NEP fixed), the representative peak frequency increases, as evident from Figs. 3b-3d. Differences in the spectrum for various angles are observed over a wide range of frequencies (roughly 3 decades). Notable differences in the spectral behavior are observed between the free jet and the partially open duct case.

\section{Conclusion}

The observed peak frequency in the partially open duct case is found to increase above the free-jet value as the angle from the duct axis is increased, and with an increase in the height of the duct inlet plane above the ground (with the nozzle exit plane fixed). The results also suggest that there is likely an optimum distance between the nozzle exit plane and the duct inlet for minimizing the sound power. The partially open duct results in increased sound levels near the duct axis relative to the free jet case. It is expected that larger reductions in sound power may be realized by increasing the duct length, increasing duct cross section (adding a diffuser) and by including absorbing liners on the duct walls. 


\section{Nomenclature}

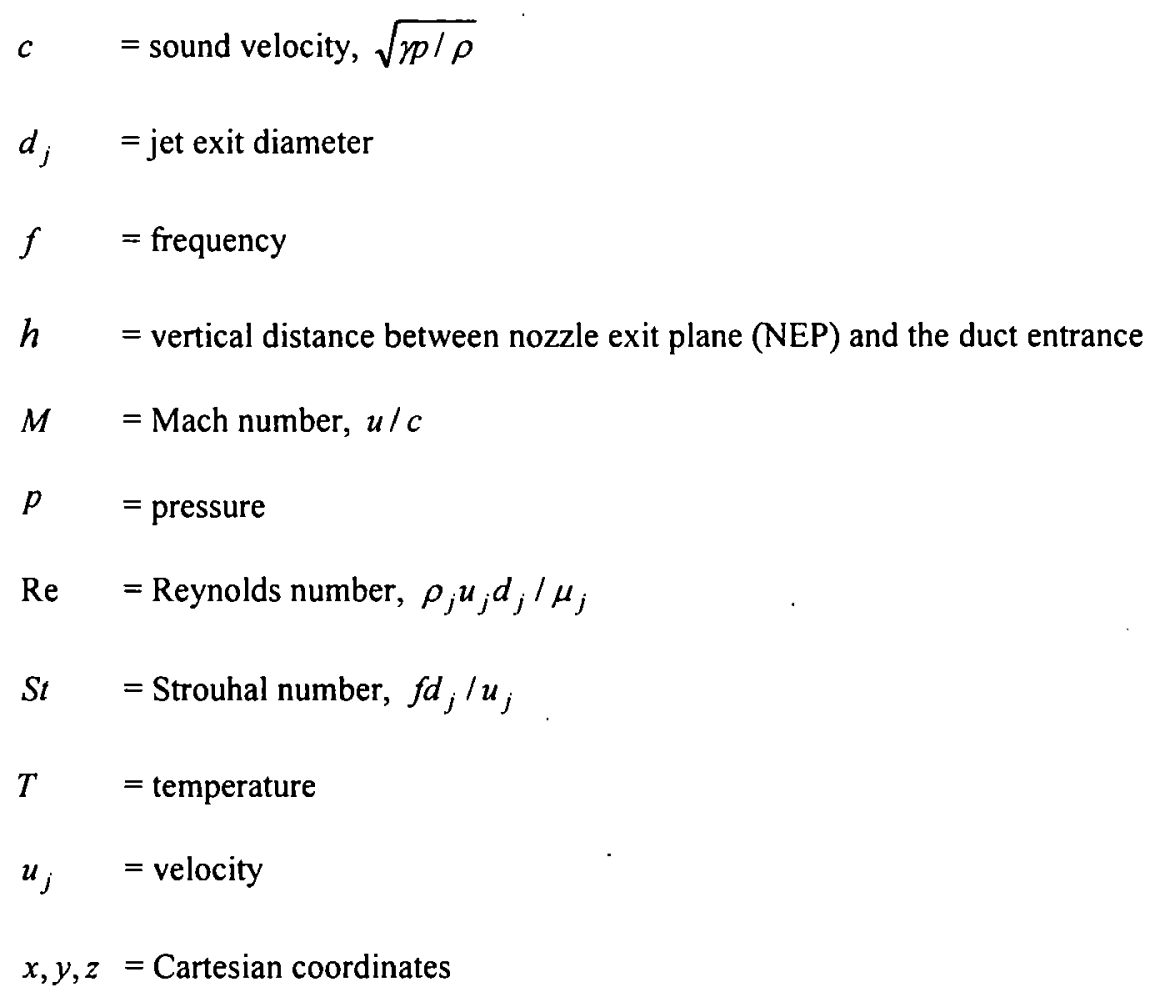

\section{Greek Symbols}

$\gamma \quad=$ isentropic exponent

$\mu \quad=$ dynamic viscosity

$\rho \quad=$ density

\section{Subscripts}

$$
\begin{array}{ll}
j & =\text { jet } \\
0 & =\text { stagnation } \\
\infty & =\text { ambient fluid }
\end{array}
$$




\section{References}

[1] Kandula, M., 2008, "On the scaling laws and similarity spectra for jet noise in subsonic and supersonic flow," Int. J. Acoustics and Vibration, 13 (1), pp. 3-16.

[2] Kandula, M., 2007, "Near field acoustics of clustered rocket engines," J. Sound and Vibration, 309, pp. 852857.

[3] Henderson, B., 2010, "Fifty years of fluidic injection for jet noise reduction," Int. J. Aeroacoustics, 9 (1\&2), pp. $91-122$.

[4] Norum, T.D., 1998, "Reductions in multi-component jet noise by water injection," AIAA Paper 98-2204.

[5] Krothapalli, A., Venkatakrishnan, L., Lourenco, L., and Greska, B., "Turbulence and noise suppression of a high-speed jet by water injection," J. Fluid Mech., 491, pp. 131-159.

[6] Kandula, M., 2008, "Prediction of turbulent jet mixing noise reduction by water injection," AIAA J., 46 (11), pp. 2714-2722.

[7] Kandula, M., 2009, "Broadband shock noise reduction in turbulent jets by water injection," Applied Acoustics, 70, pp. 1009-1014.

[8] Kandula, M., 2008, "Spectral attenuation of sound in dilute suspensions with nonlinear particle relaxation," J. Acoust. Soc. of America, 124, pp. EL-284-EL290.

[9] Eversman, W., and Roy, I.D., 1993, "Ducted fan acoustic radiation including the effects of nonuniform mean flow and acoustic treatment," AIAA-93-4424.

[10] Ozyoruk, Y., and Long, L., 1996, "Computation of sound radiated from engine inlets," AlAA Journal, 34, pp. 894-901.

[11] Kandula, M., and Vu, B., 2003, "Scale model experiments on sound propagation from a Mach 2.5 cold nitrogen jet flowing through a rigid-walled duct with a J-deflector," NASA TM-2003-211186, Kennedy Space Center.

[12] Vu, B., and Kandula, M., 2003, "Noise mitigation of ducted supersonic jets for launch exhaust management systems," JANNAF 27th Plume Technology Subcommittee Meeting, NASA Stennis Space Center, Bay St. Louis, Mississippi. 
[13] Kandula, M., 2006, "An experimental and numerical study of sound propagation from a supersonic jet passing through a rigid-walled duct with a J-deflector," Int. J. Acoustics and Vibration 11 (3), pp. $125-131$.

[14] Shapiro, A.H., The Dynamics and Thermodynamics of Compressible Fluid Flow, Vol. 1. Wiley, New York, (1953).

[15] Eldred, K.M., 1971, "Acoustic loads generated by the rocket propulsion system," NASA-SP-8072.

[16] Bishop, K.A., Ffowcs Williams, J.E., and Smith, W., 1971, "On the noise source of the unsuppressed highspeed jet,' J. Fluid Mech., 50; pp. 21-31.

[17] MacGregor, G.R., and Simcox, L.D., 1973, "The location of acoustic sources in jet flow by means of the "wall isolation" technique," AIAA-1973-1041.

[18] Krothapalli, A., Rajkuperan, E., Alvi, F., and Lourenco, L., 1999, "Flowfield and noise characteristics of a supersonic impinging jet," J. Fluid Mech., 392, pp. 155-181.

[19] Lamont, P.J., and Hunt, B.L., 1980, "The impingement of underexpanded axisymmetric jets on perpendicular and inclined plates," J. Fluid Mech., 100, pp. 471-511.

[20] Von Glahn, U., Goodykoontz, J., and Wagner, J., 1973, "Nozzle geometry and forward velocity effects on noise from CTOL engine-over-the wing concept," NASA TM-X-71453.

[21] Fink, M.R., 1975, "Scrubbing noise of externally blown flaps," AIAA-1975-469.

[22] Goebel, S.G., and Dutton, J.C., 1991, "Experimental study of compressible turbulent mixing layers," AIAA J., 29, pp. 538-546.

[23] Kandula, M., and Wilcox, D.C.W., 1995, "An examination of $k-\omega$ turbulence model for boundary layers, mixing layers and separated flows," AIAA-95-2317. 


\section{List of Captions to Tables}

Table 1. Summary of nozzle parameters.

\section{List of Captions to Figures}

Fig. la Geometry of the ducted exhaust jet configuration.

Fig. Ib A photographic view of the nozzle and duct setup.

Fig. Ic Acoustic measurement setup.

Fig. Id Microphone array height for $h / d_{j}=10$.

Fig. le Microphone array height for $h / d_{j}=5$.

Fig. If Microphone array height for $h / d_{j}=-1$.

Fig. 2a Comparison of OASPL for the free jet and the partially open duct.

Fig. 2b Comparison of OASPL for the free jet and the closed duct [13].

Fig. 3 Spectral sound power for the free jet and the partially open duct. 
Table 1. Summary of Nozzle Parameters.

\begin{tabular}{|l|l|}
\hline \multicolumn{1}{|c|}{ Parameter } & \multicolumn{1}{c|}{ Value } \\
\hline \hline Stagnation pressure, $\mathrm{N} / \mathrm{m}^{2}$ & $1.72 \times 10^{6}$ \\
\hline Stagnation temperature, $\mathrm{K}$ & 278 \\
\hline Nozzle mass flow rate, $\mathrm{kg} / \mathrm{s}$ & 0.77 \\
\hline Nozzle exit diameter, $\mathrm{mm}$ & 25.4 \\
\hline Exit pressure, $\mathrm{N} / \mathrm{m}^{2}$ & $1.01 \times 10^{5}$ \\
\hline Exit temperature, $\mathrm{K}$ & 123 \\
\hline Exit velocity, $\mathrm{m} / \mathrm{s}$ & 554.7 \\
\hline Nozzle exit Mach number & 2.5 \\
\hline Jet exit Reynolds number & $2.3 \times 10^{6}$ \\
\hline
\end{tabular}




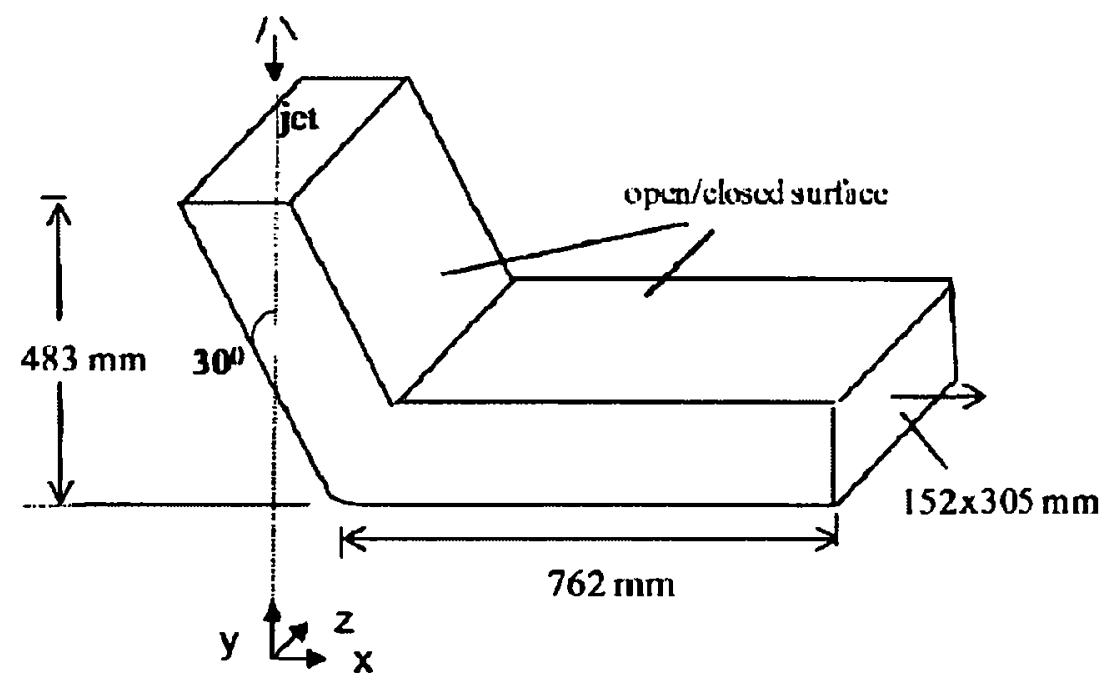

Fig. la Geometry of the ducted exhaust jet configuration.

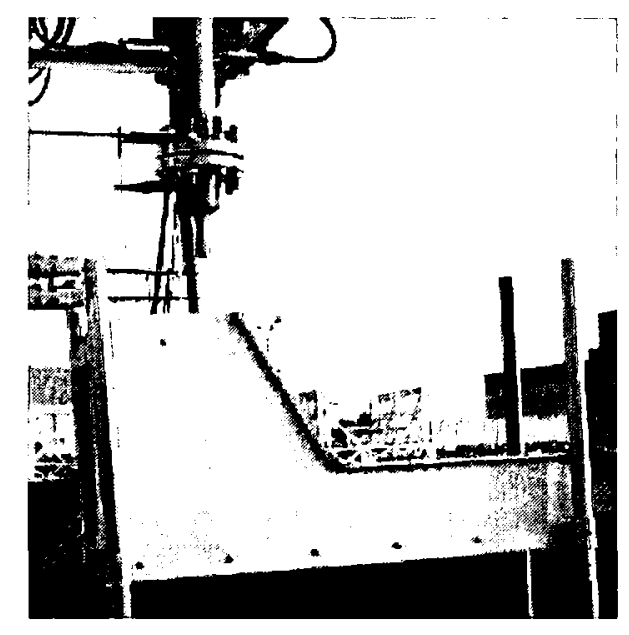

Fig. Ib A photographic view of the nozzle and duct setup. 


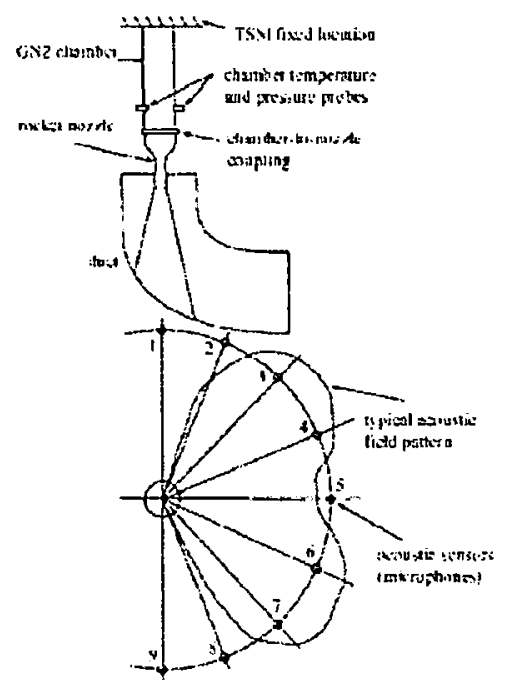

Fig. 1c Acoustic measurement setup.

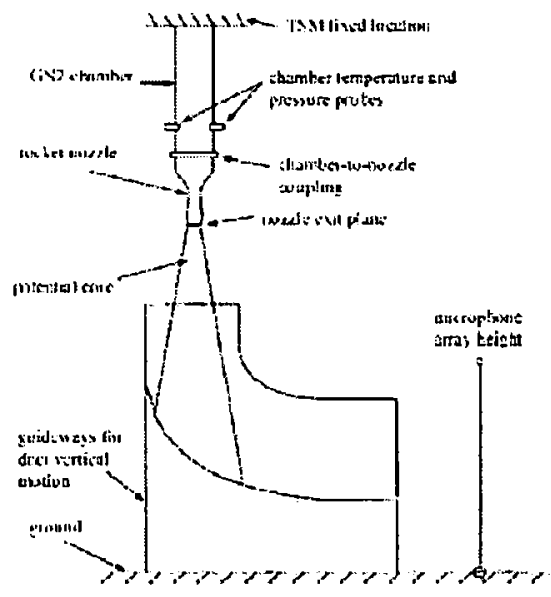

Fig. 1d Microphone array height for $h / d_{j}=10$. 


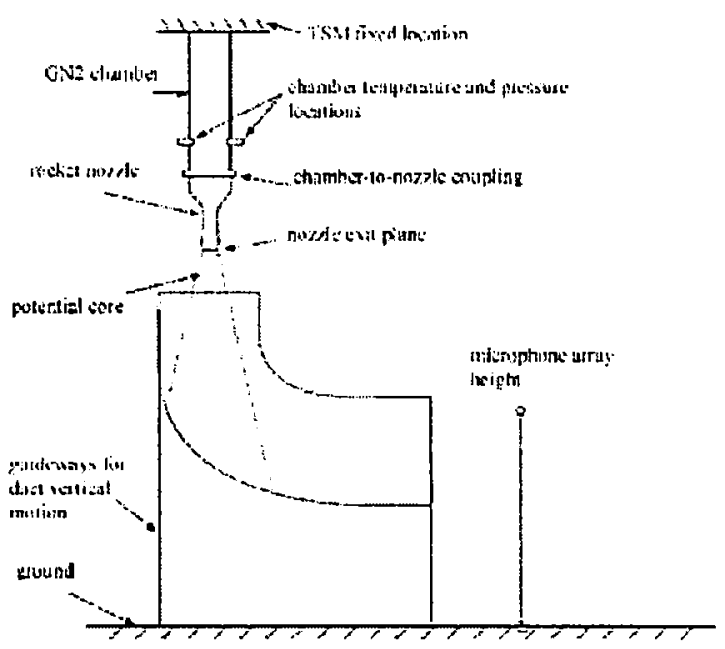

Fig. le Microphone array height for $h / d_{j}=5$.

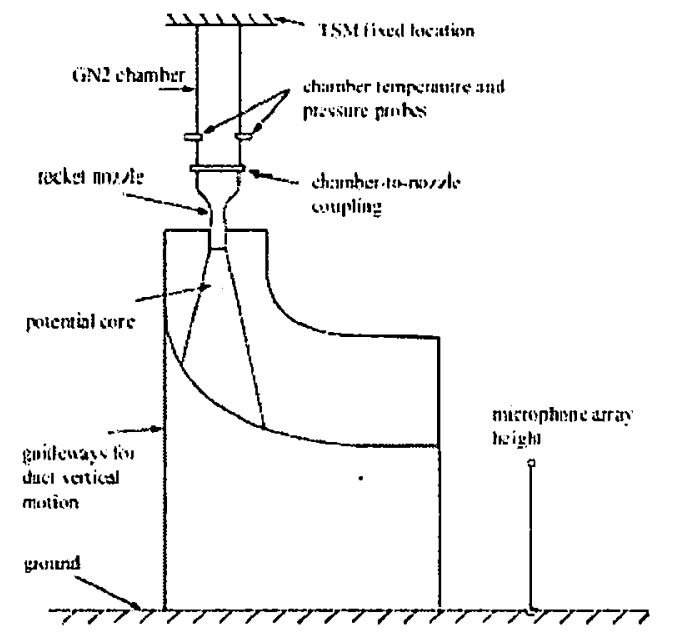

Fig. If Microphone array height for $h / d_{j}=-1$. 


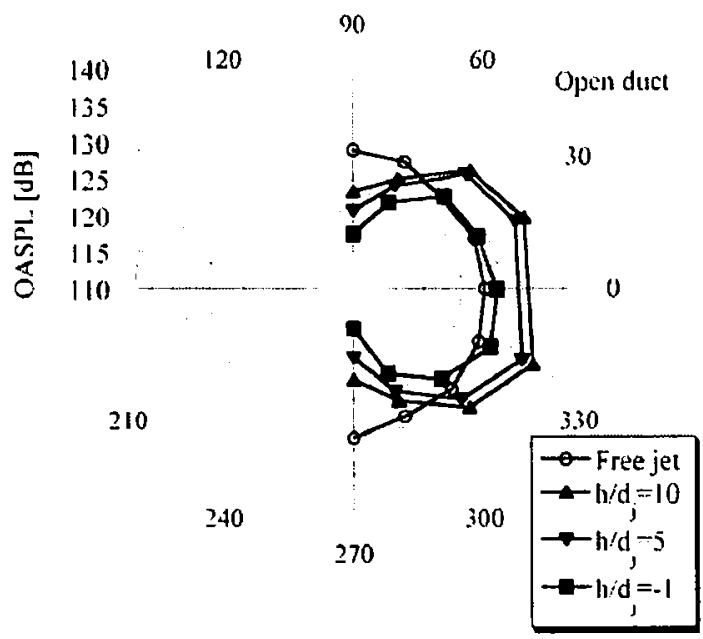

Fig. 2a Comparison of OASPL for the free jet and the partially open duct.

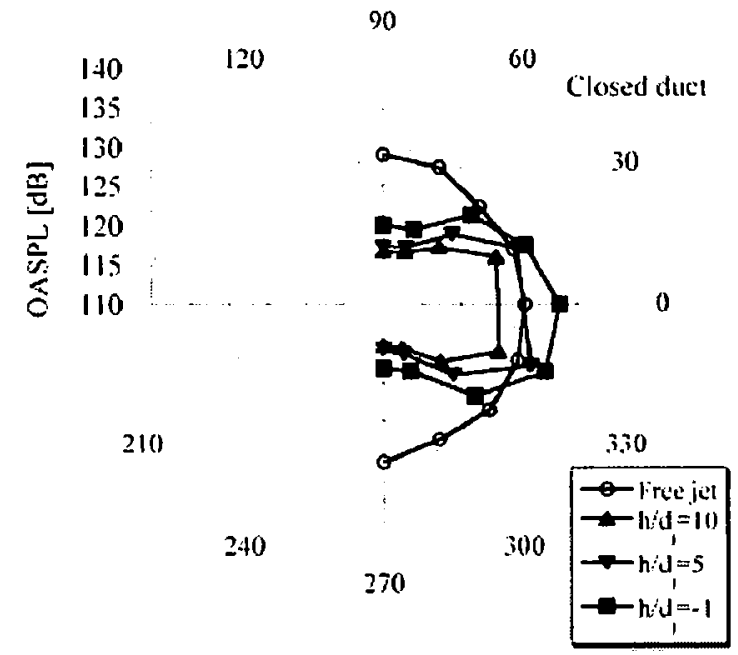

Fig. 2b Comparison of OASPL for the free jet and the closed duct [13]. 


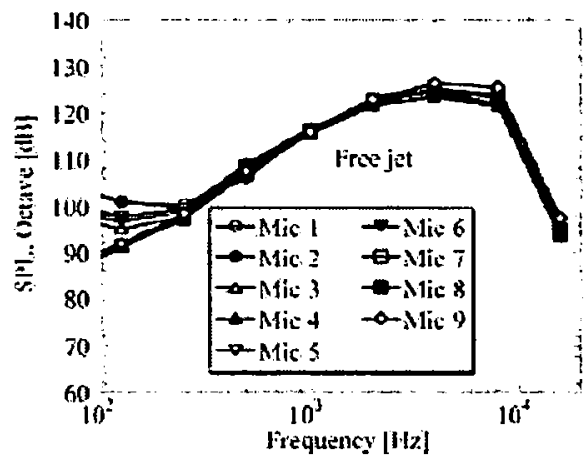

(a)

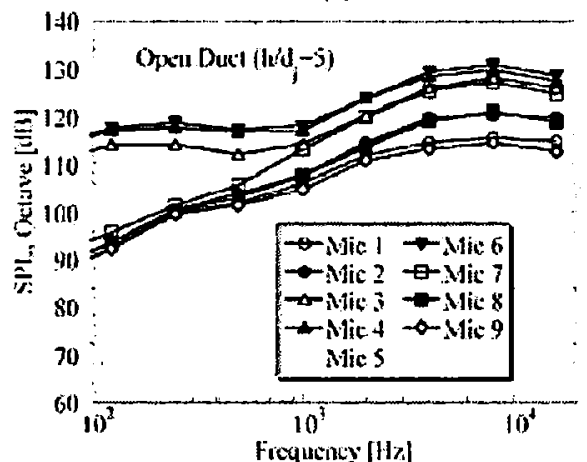

(c)

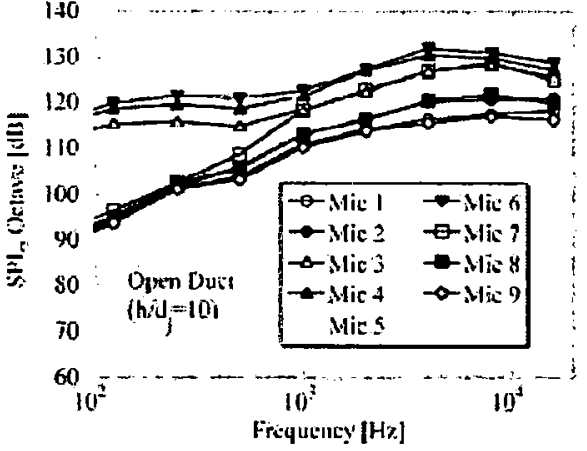

(b)

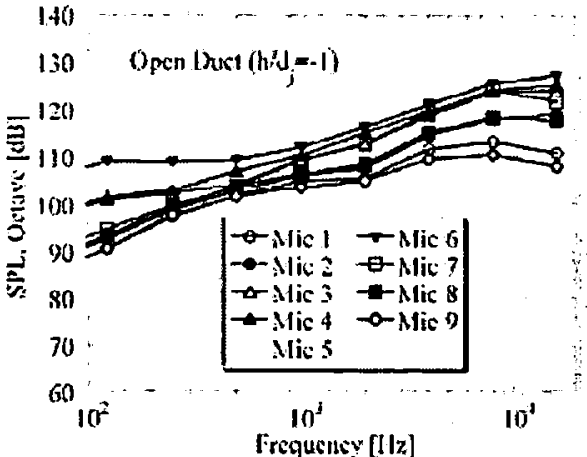

(d)

Fig. 3 Spectral sound power for the free jet and the partially open duct. 